\title{
POLARIZED YTTRIA-STABILIZED ZIRCONIA IMPROVES DURABILITY FOR DEGRADATION AND APATITE FORMATION IN SIMULATED BODY FLUID
}

\author{
Miho Nakamura $^{1 *}$, Masahiro Inuzuka ${ }^{2}$, Kazuaki Hashimoto $^{2}$, Akiko Nagai $^{1}$, Kimihiro Yamashita $^{1}$ \\ (*Corresponding author: miho.bcr@tmd.ac.jp)
}

\author{
${ }^{1}$ Institute of Biomaterials and Bioengineering, Tokyo Medical and Dental University, 2-3-10 Kanda-Surugadai, \\ Chiyoda, Tokyo 1010062 Japan \\ ${ }^{2}$ Department of Life and Environmental Sciences, Chiba Institute of Technology, 2-17-1 Tsudanuma, Narashino, \\ Chiba 2750016 Japan
}

Keywords: yttria-stabilized zirconia, phase transformation, chemical treatment, polarization

Abstract: Yttria-stabilized zirconia is currently used as an orthopedic and dental material, because of its excellent mechanical properties. In this study, we have improved the bioactivity of yttria-stabilized zirconia by a combination of electrical polarization and chemical treatment. The phase transformation from tetragonal to monoclinic $\mathrm{ZrO}_{2}$ after alkaline treatment was inhibited on positively charged yttria-stabilized zirconia surfaces compared with negatively charged and conventional surfaces. During polarization, some oxide ions move from the positively charged surface to the negatively charged surface, leading to an increase in oxygen vacancies on the positive surface and hence greater formation of $\mathrm{Zr}-\mathrm{OH}$ when this surface was exposed to alkaline solution. The bioactivity was assessed by immersing the samples in simulated body fluid and evaluating the growth of apatite on the surfaces. The combination of polarization and alkaline treatment increased the bioactivity in vitro.

(Received January 11, 2012; Accepted February 3, 2012)

\section{INTRODUCTION}

Since the late 1960s, yttria-stabilized zirconia (YSZ), especially $3 \mathrm{~mol} \% \mathrm{Y}_{2} \mathrm{O}_{3}$-doped zirconia, has been shown to be a biomaterial with excellent mechanical properties, and YSZ ceramics are currently used as ball heads in artificial hip joints and post-crowns in dental applications [1-2]. YSZ is however bioinert, meaning that no direct bonding of YSZ to natural bones occurs in vivo. In the present study, we have addressed this shortcoming by employing chemical treatments with the aim of increasing the bioactivity of YSZ.

We have recently demonstrated that the ceramic hydroxyapatite (HA) [3] may be polarized via proton migration [4], and that the polarized surfaces of HA enhanced tissue regeneration of both hard [5] and soft [6] tissues in vivo. Additionally, the polarized HA also accelerated protein adsorption [7] and cell adhesion through improved wettability of water [8]. Thus electrical polarization can have excellent chemical, biological, and biomedical effects.

Another serious problem with YSZ lies in its instability due to a tetragonal $(\mathrm{t})$ to monoclinic $(\mathrm{m})$ phase transformation at relatively low temperatures of $\left(<400^{\circ} \mathrm{C}\right)$ in moist air or hot water [9]. These phenomena are usually termed low temperature degradation (LTD). Kobayashi et al. have reported that the annealing treatment of zirconia at $65-400^{\circ} \mathrm{C}$ in water for a long time spontaneously gave rise to the transformation of tetragonal into monoclinic phase [10]. This t-m phase transformation in YSZ is reportedly accompanied by cracking on the surface due to the volume expansion of about $4-5 \%$ and degradation of mechanical strength, which can cause critical accidents in medical applications.

It is crucial to inhibit the LTD of YSZ in medical and structural applications and also to understand the role of moisture in LTD. We observed that our polarization process successfully inhibited LTD in the chemical treatments of YSZ ceramics. This report details the bioactivation and LTD-inhibition of polarized YSZ ceramics and discusses the polarization mechanisms.

\section{MATERIALS AND METHODS}

Yttria-partially stabilized zirconia powder (TZ-3Y, Tosoh, Japan) was pressed into a mold at $120 \mathrm{MPa}$. The YSZ compacts were sintered in air at $1400{ }^{\circ} \mathrm{C}$ for $1 \mathrm{~h}$. The relative density values of the sintered YSZ compacts were $c a .99 .2 \pm 0.1 \%$. The sintered YSZ samples were electrically polarized as previously described [4] with a pair of platinum electrodes at $200{ }^{\circ} \mathrm{C}$ in a direct-current (d.c.) electric field of 20 $\mathrm{V} \cdot \mathrm{cm}^{-1}$ for $30 \mathrm{~min}$ in air. The electrically polarized YSZ samples were treated with alkaline $\left(5 \mathrm{~mol} \cdot \mathrm{dm}^{-3}\right.$ $\mathrm{NaOH}$ at $95{ }^{\circ} \mathrm{C}$ for $24 \mathrm{~h}$ ) solution in commercial glass tubes. After chemical treatment, the samples were washed with deionized water and dried at $60{ }^{\circ} \mathrm{C}$ for $3 \mathrm{~h}$. The unpolarized YSZ with and without alkaline treatment were designated as $\mathrm{O}$ and YSZ, as the controls, respectively. The negatively charged YSZ and positively charged YSZ surfaces after the alkaline treatment were designated as $\mathrm{N}$ and $\mathrm{P}$, 
(A)

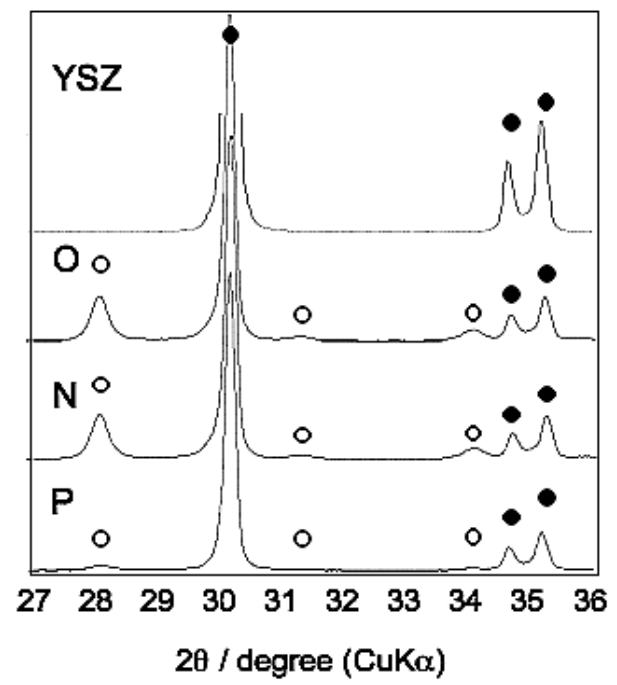

(B)

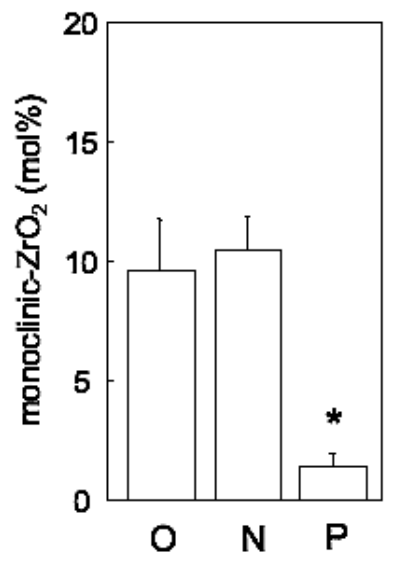

Fig. 1 (A) XRD pattern of YSZ was highly consistent with tetragonal $\mathrm{ZrO}_{2}$ (closed circles), indicating that the as-polarized YSZ surfaces consisted of a single phase of tetragonal $\mathrm{ZrO}_{2}$. The surfaces after the alkaline treatment consisted of both tetragonal $\mathrm{ZrO}_{2}$ and monoclinic $\mathrm{ZrO}_{2}$ (open circles) phases. (B) Extents of phase transformation from tetragonal $\mathrm{ZrO}_{2} \quad$ into monoclinic $\quad \mathrm{ZrO}_{2} \quad$ after alkaline treatment. $(*<0.001)$ respectively.

$\mathrm{X}$-ray diffraction (XRD) measurements for phase analysis of the alkaline-treated YSZ surfaces were performed at (RT) temperature with $\mathrm{Cu}-\mathrm{K} \alpha$ radiation at $40 \mathrm{kV}$ and $40 \mathrm{~mA}$ on a Philips PW 1700 diffractometer equipped with a graphite monochromator. The extents of phase transformation were calculated using the equation of Garvie and Nicholson [11]. Compositional analysis was carried out using x-ray photoelectron spectroscopy (XPS) on a JPS-90SX spectrometer (Japan) with $\mathrm{Al} \mathrm{K \alpha} \mathrm{X}$-rays at an analytical angle of $45^{\circ}$. The $\mathrm{C} 1 \mathrm{~s}$ peak was used for calibration of the binding energies by setting its binding energy to $284.6 \mathrm{eV}$ to correct for sample charging.

The YSZ samples were immersed in simulated body fluid (SBF) with $\mathrm{pH} 7.4$ at $37{ }^{\circ} \mathrm{C}$ for 4 and 6 days. SBF solution was prepared using the technique described by Kokubo et al. [12, 13]. After immersion in SBF, the samples were washed with deionized water and ethanol, and then dried at RT in air. The surfaces were sputtered with Pt-Pd using an ion coater (Eiko Engineering IB-2). The sputtered surfaces were observed using a scanning electron microscope (SEM, Hitachi S-2400).

\section{RESULTS \& DISCUSSION}

The XRD patterns of the YSZ surface was highly consistent with the published data for $\mathrm{ZrO}_{2}$ (ICDD no. 79-1796), indicating that the surfaces consisted of a single phase of tetragonal $\mathrm{ZrO}_{2}$ (Fig. 1A). As shown in Fig. 1A, the XRD patterns for the $\mathrm{O}, \mathrm{N}$ and $\mathrm{P}$ surfaces after the alkaline treatment consisted of the phases of tetragonal $\mathrm{ZrO}_{2}$ and monoclinic $\mathrm{ZrO}_{2}$ (ICDD no. 37-1484). The extents of the phase transformation from tetragonal $\mathrm{ZrO}_{2}$ to monoclinic
$\mathrm{ZrO}_{2}$ after alkaline treatment were 9.6, 10.4 and 1.5 mol \%, for $\mathrm{O}, \mathrm{N}$ and $\mathrm{P}$ surfaces, respectively (Fig. 1B). The phase transformation was significantly inhibited on the $\mathrm{P}$ surface. Thus alkaline treatment promotes $\mathrm{t} \rightarrow \mathrm{m}$ transformation on each surface of $\mathrm{O}$, $\mathrm{N}$ and $\mathrm{P}$ surfaces, while the $\mathrm{P}$ surface was proven to be remarkably resistant to LTD in alkaline solution.

Figure 2 shows the detailed XPS scans for oxygen 1s of $\mathrm{O}, \mathrm{N}$ and $\mathrm{P}$ surfaces after the alkaline treatment. The peak in binding energies of oxygen appeared for the alkaline-treated surfaces from $530-532 \mathrm{eV}$, which was decomposed into two peaks: $532 \mathrm{eV}$ for $\mathrm{H}_{2} \mathrm{O}$ or $\mathrm{OH}$ groups and $530 \mathrm{eV}$ for $\mathrm{ZrO}_{2}$ [14]. The ratios of the areas of $\mathrm{H}_{2} \mathrm{O}$ or $\mathrm{OH}$ group to total oxygen in $\mathrm{O}, \mathrm{N}$ and $\mathrm{P}$ surfaces were 47.3, 52.7 and $61.2 \%$, respectively (Fig. 2B). As with the alkaline treatment, more hydroxyl groups were formed on the $\mathrm{P}$ surface, compared with the $\mathrm{O}$ and $\mathrm{N}$ surfaces.

Sato et al. concluded that the phase transformation resulted from $\mathrm{Zr}-\mathrm{OH}$ formation from chemical reactions between $\mathrm{ZrO}_{2}$ and $\mathrm{H}_{2} \mathrm{O}$ on the YSZ surfaces instead of the release of zirconium and yttrium ions even in corrosive solutions at $95^{\circ} \mathrm{C}$ [15]. The mechanism of $\mathrm{Zr}-\mathrm{OH}$ formation on the YSZ surface was reported to progress in three stages: (1) the formation of hydrogen bonds between the protons of water molecules and the oxygen atoms of $\mathrm{Zr}$; (2) two concerted coupling reactions: first between the proton of water molecules and the oxygen atom of $\mathrm{Zr}$ and a second between the oxide ions of water molecules and the $\mathrm{Zr}$ atoms; (3) the cleavage of the $\mathrm{Zr}-\mathrm{O}-\mathrm{Zr}$ bonds and the formation of $\mathrm{Zr}-\mathrm{OH}$ by the phase transformation [15-17]. During the phase transformation, both the binding forces and the strain energies were decreased due to microcrack formation by the cleavage of $\mathrm{Zr}-\mathrm{O}-\mathrm{Zr}$ bonds $[15,18]$.

Deposits of bone-like apatite crystals had formed 
(A)

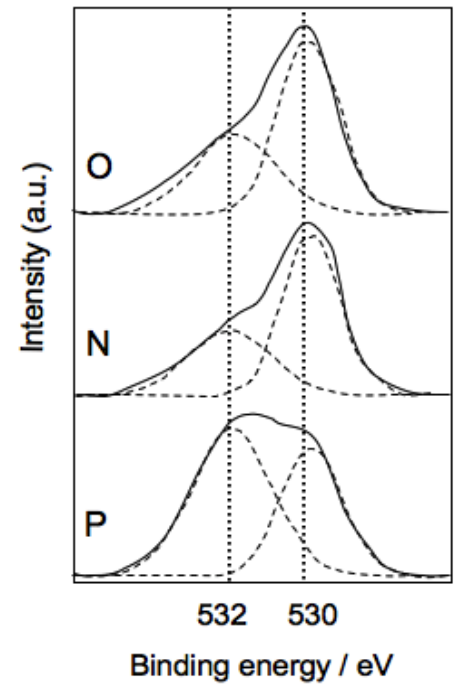

(B)

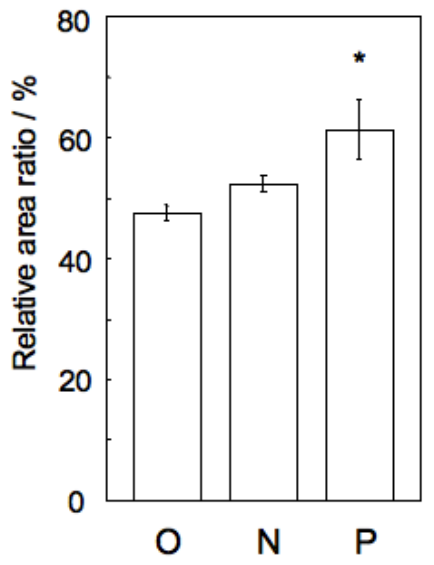

Fig. 2 (A) Detailed XPS scans for oxygen $1 \mathrm{~s}$ of $\mathrm{O}$, $\mathrm{N}$ and $\mathrm{P}$ surfaces after the alkaline treatment. (B) Ratios of the areas of $\mathrm{H}_{2} \mathrm{O}$ or $\mathrm{OH}$ groups to oxygen in YSZ samples after alkaline treatment. $(*<0.01)$ and grown to $c a$. $2 \mu \mathrm{m}$ in diameter on the alkaline-treated $\mathrm{P}$ surface after immersion for 4 days, whereas there were no deposits on the alkaline-treated $\mathrm{O}$ and $\mathrm{N}$ surfaces (data not shown). After the immersion for 6 days, deposits of bone-like apatite crystals were also observed on the alkaline-treated $\mathrm{O}$ and $\mathrm{N}$ surfaces (Fig. 3A). As shown in Fig. 3B, the XRD patterns of the deposited bone-like apatite crystals consisted of the phase for HA (ICDD no. 9-432).

The YSZ surfaces after alkaline treatment showed the phase transformation from tetragonal $\mathrm{ZrO}_{2}$ to monoclinic $\mathrm{ZrO}_{2}$ and the deposition of bone-like apatite crystals after immersion in SBF. These results, when combined with the mechanism proposed by Sato et al. [15], suggest that the $\mathrm{Zr}-\mathrm{OH}$ formed on the $\mathrm{P}$ surface by the alkaline treatment induced the nucleus formation of apatite crystals when the surfaces were immersed in SBF solution. However, although the amount of $\mathrm{OH}$ groups was larger on the alkaline-treated $\mathrm{P}$ surface than the alkaline-treated $\mathrm{O}$ and $\mathrm{N}$ surfaces, the phase transformation was inhibited on the chemically treated $\mathrm{P}$ surface. This result is incompatible with the mechanisms proposed by Sato et al.. On the other hand, Uchida et al. showed that apatite crystals were deposited on chemically treated $\mathrm{Ce}-\mathrm{TZP} / \mathrm{Al}_{2} \mathrm{O}_{3}$ by the formation of $\mathrm{Zr}-\mathrm{OH}$ without phase transformation $[13,19]$. Thus, the $\mathrm{Zr}-\mathrm{OH}$ formation on our YSZ surfaces must result not only from the aforementioned mechanism proposed by Sato et al. but also from some other mechanism.

Hydroxide ions have been reported to penetrate into the oxygen vacancies on the surface and in the lattice of $2.66(\mathrm{~mol} \%)$ yttria-partially stabilized zirconia samples sintered at $1450{ }^{\circ} \mathrm{C}$ for $2 \mathrm{~h}$ after hydrothermal treatment at high pressure, based on the measurement of the lattice constant [20].

$\mathrm{Zr}_{1-\chi} \mathrm{Y}_{\chi} \mathrm{O}_{2-\chi / 2} \square_{\chi / 2}+\delta \mathrm{H}_{2} \mathrm{O}$

$\Leftrightarrow\left(\mathrm{Zr}_{1-\chi}\right) \mathrm{O}_{2-\chi / 2-\delta}(\mathrm{OH})_{2 \delta} \square_{\chi / 2-\delta}$ where $\chi=0.0518$ and $\delta=0.0159$.

Thus, the alkaline treatment induced a reaction on the $\mathrm{P}$ surface and formed oxygen vacancies $\left(\mathrm{V}_{\mathrm{O}}\right)$ as described below [16]:

$\mathrm{Y}_{2} \mathrm{O}_{3}+2 \mathrm{Zr}_{\mathrm{Zr}}^{\times}+\mathrm{O}_{o}^{\times} \stackrel{\mathrm{ZrO}_{2}}{\longrightarrow} 2 \mathrm{Y}_{\mathrm{Zr}}^{\prime}+\mathrm{V}_{o}^{\bullet}+2 \mathrm{ZrO}_{2}$

Since there are oxygen vacancies in the YSZ structure, the likely carrier of polarization in YSZ is oxide ions. During the polarization treatment of YSZ, the oxide ions migrate to the oxygen vacancies near the negatively charged surface induced at the cathode, resulting in an increase in concentration of oxygen vacancies near the positively charged surface induced at the anode.

By the definition of Bronsted-Lowry, water molecules exist as oxonium ions or hydroxide ions in alkaline solution. Thus, the hydroxide ions are attracted to the oxygen vacancies near the positively charged YSZ surface and may enter these vacancies, inducing the formation of $\mathrm{Zr}-\mathrm{OH}$ on the $\mathrm{P}$ :

$$
\mathrm{V}_{\mathrm{o}}^{\cdot}+\mathrm{OH}^{-} \rightarrow \mathrm{OH}_{o}
$$

The LTD resistance of the $\mathrm{P}$ surface was attributed to lower cleavage of $\mathrm{Zr}-\mathrm{O}-\mathrm{Zr}$ bonds via the adsorption of water molecules.

This formation of $\mathrm{Zr}-\mathrm{OH}$ groups on both the $\mathrm{O}$ and $\mathrm{N}$ surfaces was consistent with the results of the extent of phase transformation after the chemical treatment (from XRD) and the equal amount of hydroxyl groups (from XPS). The formation of $\mathrm{Zr}-\mathrm{OH}$ groups was accelerated on the $\mathrm{P}$ surface by the selective attraction of hydroxide ions into the oxygen 
(A)
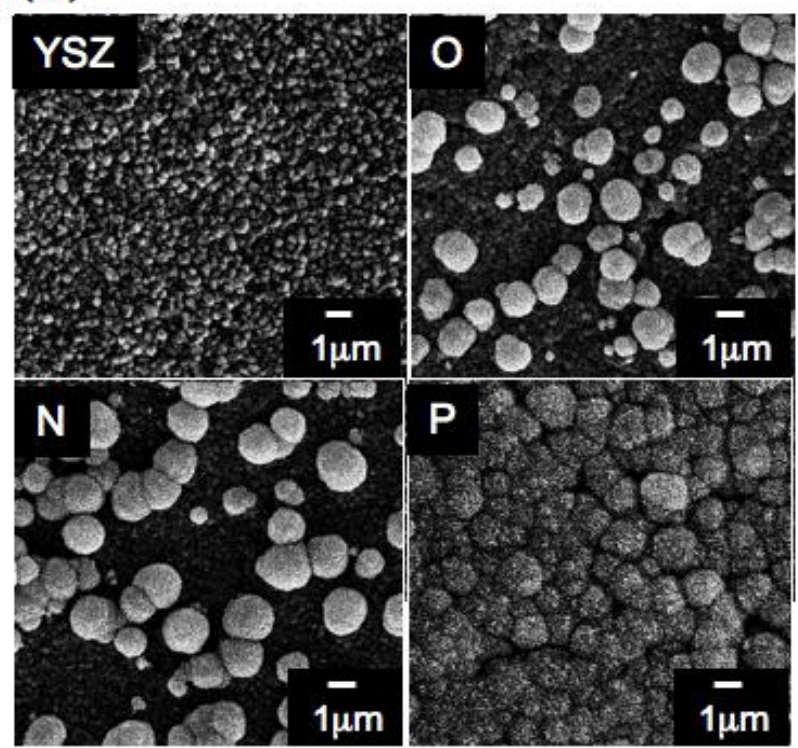

(B)

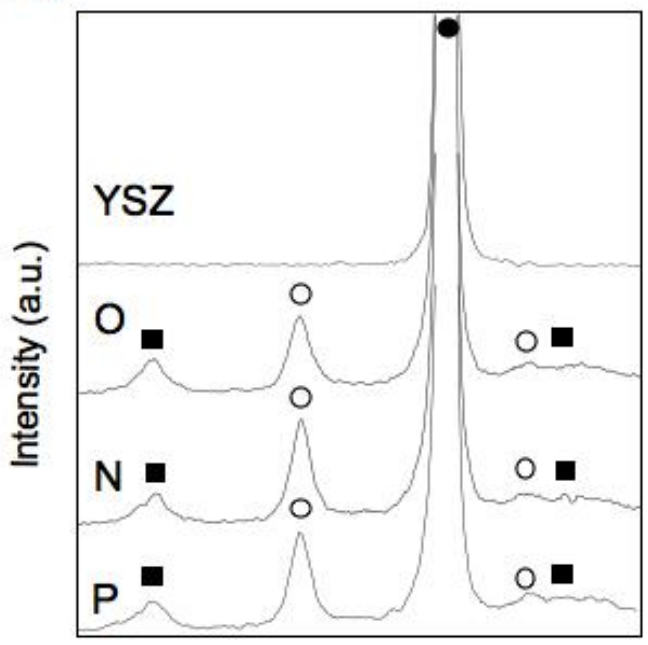

$\begin{array}{lllllllll}25 & 26 & 27 & 28 & 29 & 30 & 31 & 32 & 33\end{array}$

$2 \theta /$ degree (CuK $\alpha)$

Fig. 3 (A) SEM images of the surfaces of YSZ samples after SBF immersion. Deposition of bone-like apatite crystals of around $1 \mu \mathrm{m}$ in diameter was observed on the surfaces of the acidic-treated $\mathrm{O}, \mathrm{N}$ and $\mathrm{P}$ surfaces after SBF immersion for 6 days. (Bar=1 $\mu \mathrm{m})$ (B) The XRD patterns of the deposited bone-like apatite crystals consisted of the phase for tetragonal $\mathrm{ZrO}_{2}$ (closed circles), monoclinic $\mathrm{ZrO}_{2}$ (open circles) and HA (closed square) phases.

vacancies in comparison with the $\mathrm{O}$ and $\mathrm{N}$ surfaces. The $\mathrm{Zr}-\mathrm{OH}$ groups were considered to contribute to the nucleus formation during the deposition of bone-like apatite crystals from SBF solution.

\section{REFERENCES}

[1] Yang Y, Ong JL, Tian J. Biomaterials 24: 619-627 (2003).

[2] Chevalier J. Biomaterials 27: 535-543 (2006).

[3] Yamashita K, Oikawa N, Umegaki T. Chem Mater 12: 2697-2700 (1996).

[4] Nakamura S, Takeda H, Yamashita K. J Appl Phys 89 (10): 5386-5392 (2001).

[5] Itoh S, Nakamura S, Kobayashi T, Shinomiya K, Yamashita K. Calcified Tissue Int 78 (3): 133-142 (2006).

[6] Okabayashi R, Nakamura M, Okabayashi T, Tanaka Y, Nagai A, Yamashita K. J Biomed Mater Res Applied Biomaterials B 90: 641-646 (2009).

[7] Nakamura M, Nakamura S, Sekijima Y, Niwa K, Kobayashi T, Yamashita K. J Biomed Mater Res A 79(3): 627-634 (2006).

[8] Nakamura M, Nagai A, Hentunen T, Salonen J, Sekijima Y, Okura T, Hashimoto K, Toda Y, Monma H, Yamashita K. ACS Appl Mater Interfaces 1 (10): 2181-2189 (2009).
[9] Sato T, Shimada M. J Am Ceram Soc 68: 356-359 (1985).

[10] Kobayashi K, Kuwajima H, Masaki Y. Solid State Ionics 3/4: 489-493 (1981).

[11] Garvir RG, Nicholson PS. J Am Ceram Soc 55: 303-305 (1972).

[12] Kokubo T, Kushitani H, Sakka S, Kitsugi T, Yamamuro T. J Biomed Mater Res 24: 721-734 (1990).

[13] Uchida M, Kim HM, Kokubo T, Nawa M, Asano T, Tanaka K, Nakamura T. J Biomed Mater Res 60: 277-282 (2002).

[14] Li JF, Watanabe R, Zhanf BP, Asami K, Hashimoto K. J Am Ceram Soc 79: 3109-3112 (1996).

[15] Sato T, Fujishiro H, Endo T, Shimada M. J Mater Sci 22: 882-886 (1987).

[16] Guo X. J Am Ceram Soc 86: 1867-1873 (2003).

[17] Guo X. Chem Mater 16: 3988-3994 (2004).

[18] Aza AHD, Chevalier J, Fantozzi G, Schehl M, Torrecillas R. Biomaterials 23: 937-945 (2002).

[19] Uchida M, Kim HM, Miyaji F, Kokubo T, Nakamura T. Biomaterials 23: 313-317 (2002).

[20] Yoshimura M. Am Ceram Soc Bull 67: 1950-1955 (1988). 